\title{
Characteristic Test Of Transistor Based Multisim Software
}

\author{
Muhammad Ruswandi Djalal \\ Politeknik Negeri Ujung Pandang \\ Makassar, Indonesia \\ wandi@poliupg.ac.id
}

\author{
Herman HR \\ Politeknik Negeri Ujung Pandang \\ Makassar, Indonesia \\ hermanhr@poliupg.ac.id
}

\begin{abstract}
The purpose of this study is to determine the characteristics of the transistor before it is used in the circuit. Transistors are semiconductor devices used as amplifiers, as circuit breakers and connectors (switching), voltage stabilization, signal modulation or as other functions. Transistor performance can be seen by testing input-output characteristics. Multisim is an electronic capture and schematic simulation program that is part of a series of circuit design programs, together with NI Ultiboard. Multisim can properly simulate electronic components.
\end{abstract}

Keywords : Multisim, Transistor, Input-Output Characteristic, Semiconductor

\section{PENDAhUluan}

Komponen elektronika adalah komponen yang paling kompleks dan sensitif, tak jarang terjadi kerusakan apabila komponen yang digunakan tak seuai semestinya, misalkan kelebihan daya, arus, short, dll. Selain itu tidak semua komponen ataupun perangkat elektronika dapat dijumpai dan dibeli dengan mudah, salah satu contohnya adalah osiloskop, spektrum analizer, function generator, dll. Maka dari itu software simulasi dapat membatu proses merancang rangkaian elektronika sebelum dipatenkan langsung pada komponen. Bukan hanya itu, kitapun dapat menggunakan perangkat elektronika yang tidak dapat kita jangkau (beli dan dijumpai) untuk mengetahui karakteristik dan cara penggunaan komponen [1].

Multisim adalah sebuah software aplikasi yang berfungsi untuk menggambar dan mensimulasikan perilaku rangkaian elektronika baik analog maupun digital. Software ini dikembangkan oleh Perusahaan National Instrument yang bergerak dalam bidang produksi komponen-komponen elektronika. Multisim merupakan pengembangan dari software simulasi rangkaian elektronika yang sebelumnya terkenal dengan nama Electronics Workbench. Dengan software Multisim ini, kita dapat memodelkan sifat dari parameter rangkaian analog dan digital. Kemampuan yang disediakan Multisim adalah dapat memodelkan berbagai rancangan rangkaian, menguji suatu rangkaian dengan berbagai kemungkinan komponen, memeriksa sifat dari keseluruhan rangkaian dengan melakukan analisa AC / DC atau transient. Dengan kelengkapan sejumlah komponen yang ada kita bisa membuat kombinasi desain rangkaian yang hampir tak terbatas [2].

Pada penelitian ini akan dilakukan percobaan pengujian karakteristik transistor, yaitu karakteristik input dan output dengan menggunakan software Multisim.

\section{TEORI DASAR}

\section{A. Transistor [3]}

Transistor yang dimaksud disini adalah transistor sambungan dwi - kutub yang di singkat dengan BJT (bipolar junction transistor). Dalam istilah sehari-hari BJT dikenal dengan nama transistor saja. Cara beroperasinya adalah bergantung pada dua jenis muatan (yaitu elektron dan atau lubang) serta dikenal oleh arus.

Dikenal pula transistor tipe sambungan namun cara kerjanya dikendalikan oleh tegangan serta bergantung pada satu jenis muatan yaitu lubang saja atau elektron saja. Transistor seperti ini disebut JFET (junction field effect transistor) atau disingkat FET (field effect transistor). Gambar 1 memperlihatkan simbol-simbol transistor NPN dan PNP.

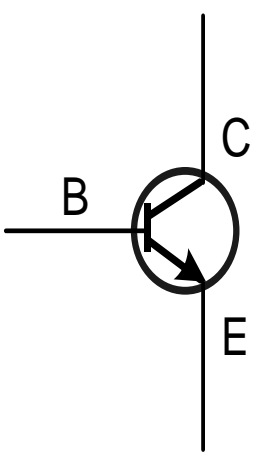

(a)

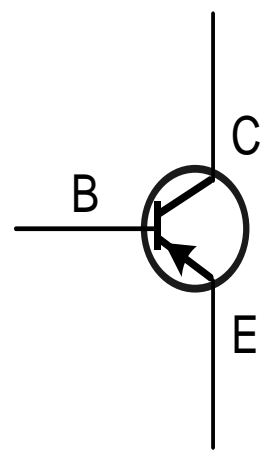

(b)
Gambar 1 Simbol-simbol transistor. (a) Tipe NPN. (b) Tipe PNP 


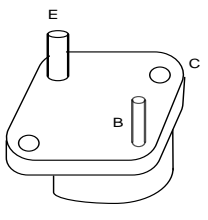

(a)

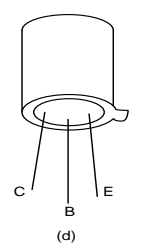

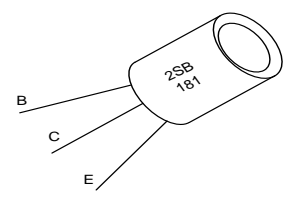

(b)

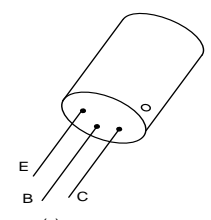

(c)

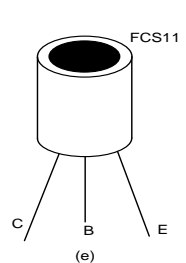

(e)

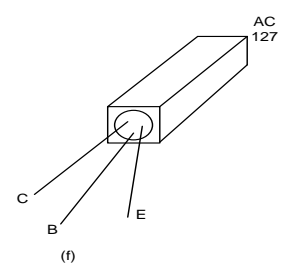

Gambar 2 Beberapa wujud transistor

Sebelum memasang transistor dalam rangkaian maka terlebih dahulu harus diketahui yang mana emiter (E), kolektor (C), atau basis (B). Biasanya pabrik-pabrik pembuat memberi tanda lingkaran atau titik merah (atau tanda lain) di dekat kaki C seperti pada Gambar 3 (a). Jika dilihat dari atas, maka urutan kaki-kaki dalam arah putaran jarum jam adalah C-B-E. Biasa juga kepingan lidah kecil yang menjorok menandai kaki E. Dan urutan kaki-kaki teansistor menurut arah putaran jarum jam jika dilihat dari atas adalah E-C-B. Urutan ini adalah sama saja dengan urutan yang pertama diatas.
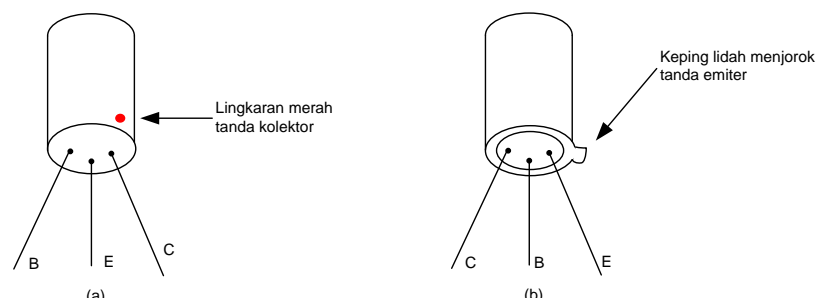

(a)

Gambar 3 Penandaan kaki-kaki transistor. (a) Bintik merah didekat kolektor. (b) keping lidah menjorok di dekat emiter.

Karakteristik / kurva output pada rangkaian emiter sekutu didefenisikan sebagai kurva yang menyatakan arus kolektor $\left(\mathrm{I}_{\mathrm{C}}\right)$ sebagai fungsi dari tegangan kolektor - emiter $\left(\mathrm{V}_{\mathrm{CE}}\right)$ pada keadaan arus basis $\left(\mathrm{I}_{\mathrm{B}}\right)$ yang konstan. Kurva output disebut pula kurva kolektor [6].

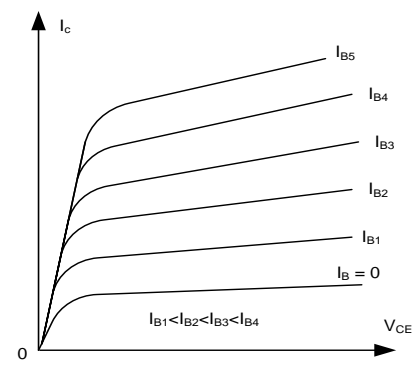

(a)

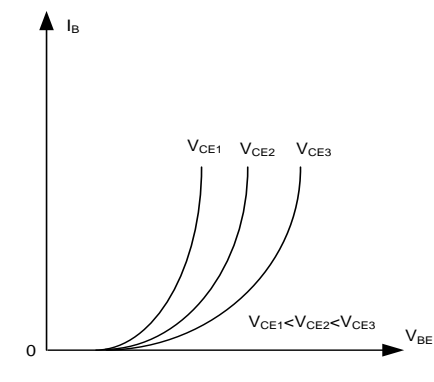

(b)
Gambar 4 Karakteristik rangkaian emiter - sekutu. (a) Karakteristik output. (b) Karakteristik input
Karakteristik / kurva input pada rangkaian emiter - sekutu didefenisikan sebagai kurva yang menyatakan arus basis $\left(\mathrm{I}_{\mathrm{B}}\right)$ sebagai fungsi dari tegangan basis - emiter $\left(\mathrm{V}_{\mathrm{BE}}\right)$ pada keadaan tegangan kolektor - emiter $\left(\mathrm{V}_{\mathrm{CE}}\right)$ yang konstan [7].

\section{B. Multisim}

NI Multisim (sebelumnya MultiSIM) adalah program penangkapan dan simulasi skematik elektronik yang merupakan bagian dari rangkaian program desain sirkuit, bersama dengan NI Ultiboard. Multisim adalah salah satu dari sedikit program desain rangkaian yang menggunakan simulasi perangkat lunak asli Berkeley SPICE. Multisim pada awalnya dibuat oleh perusahaan bernama Electronics Workbench, yang sekarang merupakan divisi dari National Instruments. Multisim termasuk simulasi mikrokontroler (sebelumnya dikenal sebagai MultiMCU), serta fitur impor dan ekspor terintegrasi ke perangkat lunak tata letak Papan Sirkuit Cetak di suite, NI Ultiboard [4].

Multisim banyak digunakan di dunia akademis dan industri untuk pendidikan sirkuit, desain skema elektronik dan simulasi SPICE. Antarmuka pengguna Multisim terdiri dari unsur-unsur dasar sebagai berikut [5]:

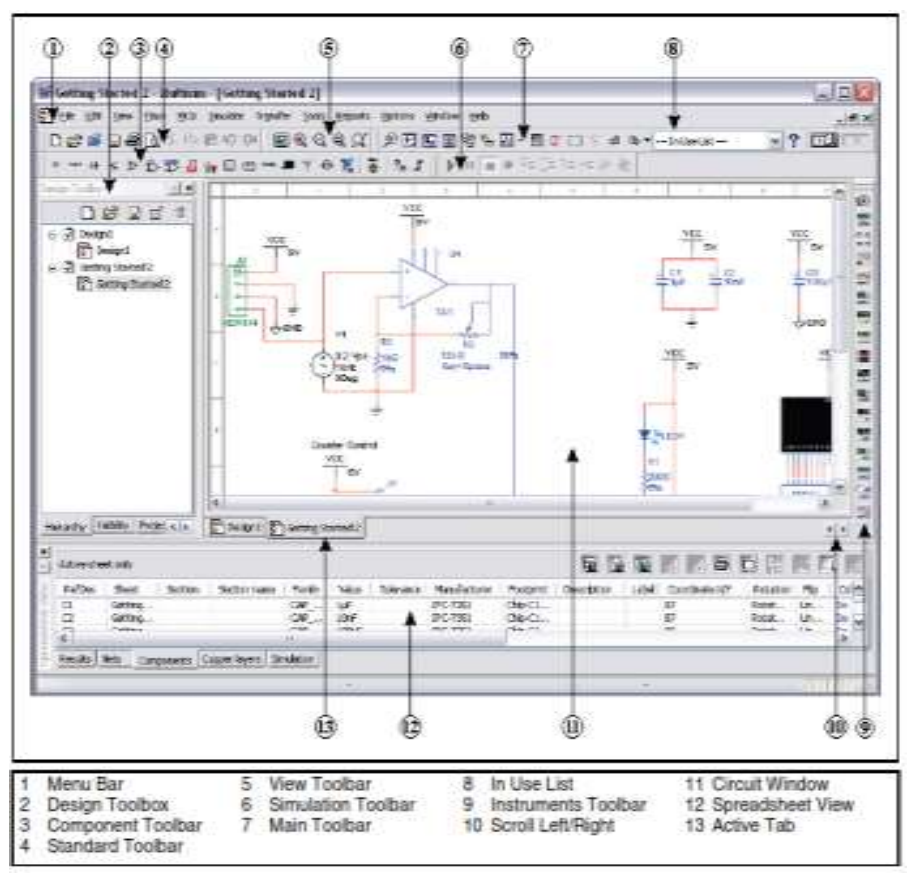

Gambar 5 Tampilan Multisim

Menu Bar, di mana Anda menemukan perintah untuk semua fungsi.

Design Toolbox, di mana Anda dapat menavigasi melalui berbagai jenis file dalam proyek (skema, PCB, laporan), melihat hirarki skema ini dan menampilkan atau menyembunyikan lapisan yang berbeda.

Component Toolbal, berisi tombol yang Anda gunakan untuk memilih komponen dari database Multisim untuk penempatan dalam skema Anda. 
Standar Toolbar berisi tombol untuk fungsi umumdilakukan seperti bintang, Print, Cut, dan Paste

View Toolbar berisi tombol untuk memodifikasi cara layar ditampilkan.

Simulation Toolbar berisi tombol untuk Start, Stop, dan fungsi simulasi lainnya.

Main Toolbar berisi tombol untuk fungsi Multisim umum.

In Use List daftar semua komponen yang digunakan dalam desain.

Instrumen Toolbar berisi tombol untuk setiap instrumen.

Circuit Window (atau ruang kerja) adalah di mana Anda membangun rangkaian yang akan Anda desain.

Spreadsheet View memungkinkan tampilan canggih cepat dan pengeditan parameter termasuk rincian komponen seperti trace kaki, RefDes, atribut dan kendala desain. Anda dapat mengubah parameter untuk beberapa atau semua komponen dalam satu langkah dan melakukan sejumlah fungsi lainnya.

\section{Metodologi PENELITIAN}

\section{A. Prosedur Percobaan}

1. Karakteristik Output

a) Buat rangkaian seperti pada Gambar 6

b) Mengatur tegangan output power supply pada suatu nilai yang tertentu, kemudian mengatur potensiometer $\mathrm{V}_{\mathrm{R} 1}$ untuk mendapatkan harga arus basis yang terkecil. Kemudian mencatat arus kolektor, tegangan kolektor - emiter, dan tegangan basis - emiter.

c) Dalam keadaan arus basis pada langkah no. 2 diatas yang konstan, aturlah potensiometer $V_{R 2}$ untuk mendapatkan nilai yang lain dari arus kolektor dan tegangan kolektor - emiter. Pada setiap pengaturan potensiometer $\mathrm{V}_{\mathrm{R} 2}$, dicatat kembali besar kolektor, tegangan kolektor - emiter, dan tegangan basis emiter. Masukkan data anda ke dalam tabel yang telah disediakan. [jika arus basis cenderung berubah dalam pengaturan potensiometer $\mathrm{V}_{\mathrm{R} 2}$, aturlah potensiometer $\mathrm{V}_{\mathrm{R} 1}$ agar arus basis kembali ke keadaan yang di pertahankan konstan].

d) Mengulangi langkah di atas untuk arus basis lainnya yang di konstankan.

2. Karakteristik Input

a) Mengaturlah potensiometer $V_{R 2}$ untuk mendapatkan harga tegangan kolektor - emiter. Kemudian mencatat arus basis, tegangan basis - emiter, dan arus kolektor.

b) Dalam keadaan tegangan kolektor - emiter pada langkah di atas yang konstan, potensiometer $V_{R 1}$ diatur untuk mendapatkan harga yang lain dari arus basis dan tegangan basis - emiter. Pada setiap pengaturan potensiometer $\mathrm{V}_{\mathrm{R} 1}$, arus basis, tegangan basis - emiter, dan arus kolektor dicatat. [jika tegangan kolektor - emiter cenderung berubah dalam pengaturan potensiometer $\mathrm{V}_{\mathrm{R} 1}$, aturlah potensiometer $\mathrm{V}_{\mathrm{R} 2}$ agar tegangan kolektor - emiter kembali ke keadaan yang di pertahankan konstan]. c) Mengulangi langkah di atas untuk tegangan kolektor emiter lainnya yang di konstankan.

\section{B. Gambar Rangkaian}

Beberapa komponen yang digunakan antara lain, Catu daya $d c$ variabel (power supply), Multimeter, Amperemeter, Voltmeter, Transistor BC 109, Potensiometer $(1 \mathrm{k} \Omega$ dan 10 $\mathrm{k} \Omega$ ), Resistor $33 \mathrm{k} \Omega$.

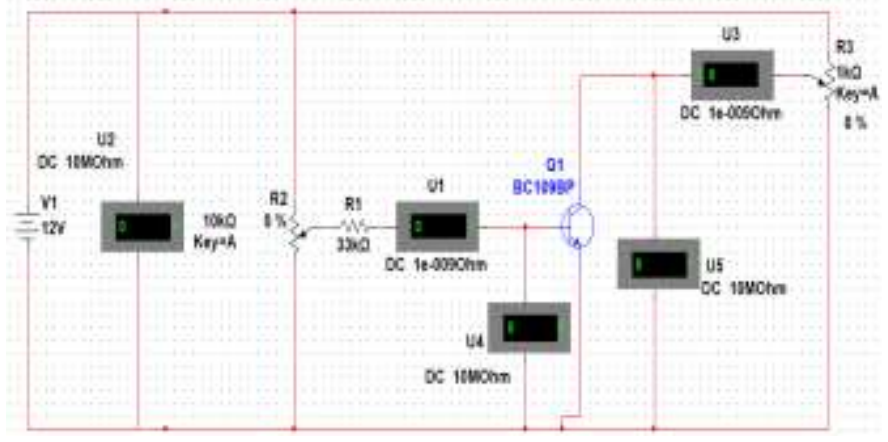

Gambar 6 Rangkaian percobaan pengujian karakteristik transistor

\section{HASIL DAN PEMBAHASAN}

\section{A. Hasill Percobaan}

Berikut hasil simulasi pengujian karakteristik transistor dengan menggunakan software Multisim. Percobaan dilakukan sebanyak 10 kali, untuk percobaan karakteristik output, digunakan tegangan konstan sebesar 12 Volt, dan karakteristik input maksimal 15 Volt. Hasil percobaan ditunjukkan pada table 1 dan 2, sedangkan gambar pengujian pada gambar 7 dan 8 .

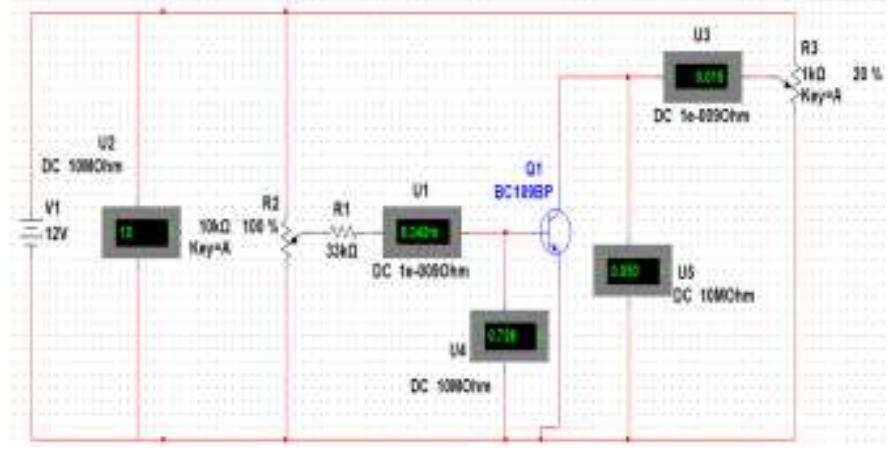

Gambar 7 Karakteristik Output

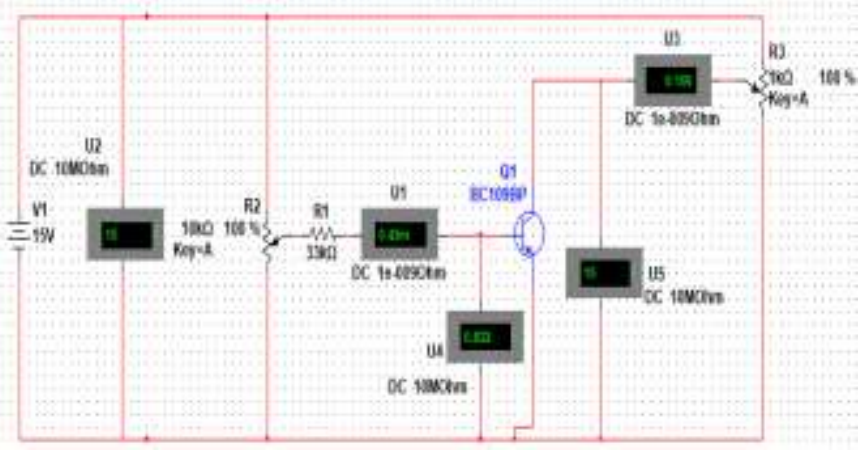

Gambar 8 Karakteristik Input 
TABEL 1 HASIL PERCOBAAN KARAKTERISTIK OUTPUT

\begin{tabular}{|c|c|c|c|c|c|c|}
\hline \multirow{2}{*}{ No } & \multicolumn{3}{|c|}{$\mathbf{I}_{\mathbf{B}}=\mathbf{0 . 0 6 6} \mathbf{~ m A}$} & \multicolumn{3}{c|}{$\mathbf{I}_{\mathbf{B}}=\mathbf{0 . 1 1 5} \mathbf{~ m A}$} \\
\cline { 2 - 7 } & $\begin{array}{c}\mathbf{I}_{\mathbf{C}} \\
{[\mathbf{A}]}\end{array}$ & $\begin{array}{c}\mathbf{V}_{\mathbf{C E}} \\
{[\mathbf{V}]}\end{array}$ & $\begin{array}{c}\mathbf{V}_{\mathbf{B E}} \\
{[\mathbf{V}]}\end{array}$ & $\begin{array}{c}\mathbf{I}_{\mathbf{C}} \\
{[\mathbf{A}]}\end{array}$ & $\begin{array}{c}\mathbf{V}_{\mathbf{C E}} \\
{[\mathbf{V}]}\end{array}$ & $\begin{array}{c}\mathbf{V}_{\mathbf{B E}} \\
{[\mathbf{V}]}\end{array}$ \\
\hline 1 & 0.012 & 0.112 & 0.713 & 0.012 & 0.081 & 0.716 \\
\hline 2 & 0.014 & 0.130 & 0.719 & 0.014 & 0.090 & 0.721 \\
\hline 3 & 0.016 & 0.158 & 0.724 & 0.017 & 0.1 & 0.726 \\
\hline 4 & 0.018 & 0.367 & 0.728 & 0.020 & 0.113 & 0.732 \\
\hline 5 & 0.019 & 1.320 & 0.728 & 0.023 & 0.134 & 0.739 \\
\hline 6 & 0.019 & 2.611 & 0.729 & 0.029 & 0.194 & 0.749 \\
\hline 7 & 0.020 & 4.299 & 0.729 & 0.031 & 1.826 & 0.751 \\
\hline 8 & 0.020 & 6.390 & 0.729 & 0.032 & 4.417 & 0.752 \\
\hline 9 & 0.021 & 8.931 & 0.730 & 0.034 & 7.755 & 0.753 \\
\hline 10 & 0.022 & 12 & 0.731 & 0.036 & 12 & 0.754 \\
\hline
\end{tabular}

TABEL 2 HASIL PERCOBAAN KARAKTERISTIK OUTPUT (LANJUTAN)

\begin{tabular}{|c|c|c|c|c|c|c|c|c|c|}
\hline \multirow{2}{*}{$\begin{array}{l}\mathbf{N} \\
\mathbf{0}\end{array}$} & \multicolumn{3}{|c|}{$I_{B}=0.148 \mathrm{~mA}$} & \multicolumn{3}{|c|}{$I_{B}=0.219 \mathrm{~mA}$} & \multicolumn{3}{|c|}{$I_{B}=0.342 \mathrm{~mA}$} \\
\hline & $\begin{array}{c}\text { IC } \\
\text { [A] }\end{array}$ & $\begin{array}{l}\mathbf{V}_{\mathbf{C E}} \\
{[\mathbf{V}]}\end{array}$ & $\begin{array}{l}V_{B E} \\
{[\mathbf{V}]}\end{array}$ & $\begin{array}{c}\mathbf{I C} \\
{[\mathbf{A}]}\end{array}$ & $\begin{array}{l}\mathbf{V}_{\mathbf{C E}} \\
{[\mathbf{V}]}\end{array}$ & $\begin{array}{l}\mathbf{V}_{\text {BE }} \\
{[\mathrm{V}]}\end{array}$ & $\begin{array}{c}\mathbf{I} \mathbf{C} \\
{[\mathbf{A}]}\end{array}$ & $\begin{array}{l}\mathbf{V}_{\mathrm{CE}} \\
{[\mathrm{V}]}\end{array}$ & $\begin{array}{l}\mathbf{V}_{\mathbf{B E}} \\
{[\mathbf{V}]}\end{array}$ \\
\hline & 0.01 & 0.06 & 0.71 & 0.01 & 0.05 & 0.72 & 0.01 & 0.04 & 0.72 \\
\hline 1 & 1 & 6 & 4 & 3 & 9 & 0 & 3 & 7 & 4 \\
\hline 2 & 0.01 & 0.07 & 0.72 & 0.01 & 0.06 & 0.72 & 0.01 & 0.05 & 0.72 \\
\hline 2 & 4 & 5 & 0 & 5 & 5 & 4 & 5 & 3 & 8 \\
\hline 3 & 0.01 & 0.08 & 0.72 & 0.01 & 0.07 & 0.72 & 0.01 & 0.05 & 0.73 \\
\hline 3 & 6 & 3 & 4 & 7 & 2 & 9 & 7 & 8 & 2 \\
\hline 4 & 0.02 & 0.09 & 0.73 & 0.02 & 0.08 & 0.73 & 0.02 & 0.06 & 0.73 \\
\hline 4 & 0 & 8 & 3 & 0 & 1 & 4 & 0 & 6 & 7 \\
\hline 5 & 0.02 & 0.11 & 0.74 & 0.02 & 0.09 & 0.74 & 0.02 & 0.07 & 0.74 \\
\hline & 4 & 3 & 0 & 4 & 2 & 1 & 4 & 5 & 4 \\
\hline 6 & 0.02 & 0.13 & 0.74 & 0.03 & 0.10 & 0.75 & 0.03 & 0.08 & 0.75 \\
\hline & 9 & 9 & 9 & 0 & 9 & 1 & 0 & 9 & 3 \\
\hline 7 & $\begin{array}{c}0.03 \\
8\end{array}$ & $\begin{array}{c}0.38 \\
6\end{array}$ & $\begin{array}{c}0.76 \\
2\end{array}$ & $\begin{array}{c}0.03 \\
9\end{array}$ & $\begin{array}{c}0.14 \\
1\end{array}$ & $\begin{array}{c}0.76 \\
5\end{array}$ & $\begin{array}{c}0.03 \\
9\end{array}$ & 0.11 & 0.76 \\
\hline 8 & $\begin{array}{c}0.04 \\
0\end{array}$ & $\begin{array}{c}3.25 \\
4\end{array}$ & $\begin{array}{c}0.76 \\
3\end{array}$ & $\begin{array}{c}0.05 \\
3\end{array}$ & $\begin{array}{c}1.13 \\
1\end{array}$ & $\begin{array}{c}0.78 \\
1\end{array}$ & $\begin{array}{c}0.05 \\
9\end{array}$ & 0.16 & $\begin{array}{c}0.79 \\
0\end{array}$ \\
\hline 9 & 0.04 & 7.05 & 0.76 & 0.05 & 5.74 & 0.78 & 0.07 & 3.82 & 0.80 \\
\hline & 2 & 0 & 4 & 6 & 1 & 3 & 8 & 5 & 8 \\
\hline 10 & $\begin{array}{c}0.04 \\
4\end{array}$ & 12 & $\begin{array}{c}0.76 \\
6\end{array}$ & $\begin{array}{c}0.06 \\
1\end{array}$ & 12 & $\begin{array}{c}0.78 \\
6\end{array}$ & $\begin{array}{c}0.08 \\
6\end{array}$ & 12 & $\begin{array}{c}0.81 \\
3\end{array}$ \\
\hline
\end{tabular}

TABEL 3 HASIL PERCOBAAN KARAKTERISTIK INPUT

\begin{tabular}{|c|c|c|c|c|c|c|}
\hline \multirow{2}{*}{ No } & \multicolumn{3}{|c|}{$\mathbf{V}_{\mathbf{C E}}=\mathbf{5} \mathbf{~ V}$} & \multicolumn{3}{c|}{$\mathbf{V}_{\mathbf{C E}}=\mathbf{7} \mathbf{~ V}$} \\
\cline { 2 - 7 } & $\begin{array}{c}\mathbf{I}_{\mathbf{B}} \\
{[\mathbf{m A}]}\end{array}$ & $\begin{array}{c}\mathbf{V}_{\text {BE }} \\
{[\mathbf{V}]}\end{array}$ & $\begin{array}{c}\mathbf{I}_{\mathbf{C}} \\
{[\mathbf{A}]}\end{array}$ & $\begin{array}{c}\mathbf{I}_{\mathbf{B}} \\
{[\mathbf{m A}]}\end{array}$ & $\begin{array}{c}\mathbf{V}_{\mathbf{B E}} \\
{[\mathbf{V}]}\end{array}$ & $\begin{array}{c}\mathbf{I}_{\mathbf{C}} \\
{[\mathbf{A}]}\end{array}$ \\
\hline 1 & 0.017 & 0.684 & 0.005 & 0.021 & 0.691 & 0.006 \\
\hline 2 & 0.023 & 0.694 & 0.007 & 0.030 & 0.703 & 0.009 \\
\hline 3 & 0.037 & 0.709 & 0.011 & 0.041 & 0.712 & 0.013 \\
\hline 4 & 0.051 & 0.720 & 0.016 & 0.060 & 0.726 & 0.018 \\
\hline 5 & 0.058 & 0.724 & 0.018 & 0.079 & 0.737 & 0.024 \\
\hline 6 & 0.064 & 0.729 & 0.020 & 0.099 & 0.746 & 0.029 \\
\hline 7 & 0.071 & 0.733 & 0.022 & 0.119 & 0.754 & 0.035 \\
\hline 8 & 0.087 & 0.740 & 0.026 & 0.140 & 0.762 & 0.040 \\
\hline 9 & 0.103 & 0.747 & 0.030 & 0.164 & 0.769 & 0.045 \\
\hline 10 & 0.129 & 0.757 & 0.036 & 0.189 & 0.777 & 0.051 \\
\hline
\end{tabular}

TABEL 4 HASIL PERCOBAAN KARAKTERISTIK INPUT (LANJUTAN)

\begin{tabular}{|c|c|c|c|c|c|c|c|c|c|}
\hline \multirow[b]{2}{*}{$\begin{array}{l}\mathbf{N} \\
\mathbf{0}\end{array}$} & \multicolumn{3}{|c|}{$\mathrm{V}_{\mathrm{CE}}=10 \mathrm{~V}$} & \multicolumn{3}{|c|}{$V_{C E}=12 \mathrm{~V}$} & \multicolumn{3}{|c|}{$V_{C E}=15 \mathrm{~V}$} \\
\hline & $\begin{array}{c}\mathbf{I B}_{\mathbf{B}} \\
{[\mathbf{m A}} \\
]\end{array}$ & $\begin{array}{l}\mathbf{V}_{\text {BE }} \\
{[\mathbf{V}]}\end{array}$ & $\begin{array}{c}\mathbf{I} \mathbf{c} \\
{[\mathbf{A}]}\end{array}$ & $\begin{array}{c}\mathbf{I B}_{\mathbf{B}} \\
{[\mathrm{mA}} \\
]\end{array}$ & $\begin{array}{l}\mathbf{V}_{\mathrm{BE}} \\
{[\mathbf{V}]}\end{array}$ & $\begin{array}{c}\text { IC } \\
{[\mathbf{A}]}\end{array}$ & $\begin{array}{c}\mathbf{I B}_{\mathbf{B}} \\
{[\mathrm{mA}} \\
]\end{array}$ & $\begin{array}{l}\mathbf{V}_{\mathrm{BE}} \\
{[\mathbf{V}]}\end{array}$ & $\begin{array}{c}\mathbf{I} \mathbf{c} \\
{[\mathbf{A}]}\end{array}$ \\
\hline 1 & 0.01 & 0.67 & 0.00 & $\begin{array}{c}0.01 \\
6\end{array}$ & $\begin{array}{c}0.68 \\
4\end{array}$ & $\begin{array}{c}0.00 \\
5\end{array}$ & $\begin{array}{c}0.02 \\
5\end{array}$ & $\begin{array}{c}0.69 \\
7\end{array}$ & $\begin{array}{c}0.00 \\
8\end{array}$ \\
\hline 2 & $\begin{array}{c}0.03 \\
9\end{array}$ & 0.71 & 0.01 & $\begin{array}{c}0.05 \\
0\end{array}$ & $\begin{array}{c}0.72 \\
0\end{array}$ & 0.01 & $\begin{array}{c}0.06 \\
8\end{array}$ & $\begin{array}{c}0.73 \\
2\end{array}$ & 0.02 \\
\hline 3 & $\begin{array}{c}0.06 \\
6\end{array}$ & $\begin{array}{c}0.73 \\
0\end{array}$ & $\begin{array}{c}0.02 \\
1\end{array}$ & $\begin{array}{c}0.08 \\
3\end{array}$ & $\begin{array}{c}0.74 \\
0\end{array}$ & $\begin{array}{c}0.02 \\
7\end{array}$ & $\begin{array}{c}0.10 \\
8\end{array}$ & $\begin{array}{c}0.75 \\
2\end{array}$ & $\begin{array}{c}0.03 \\
5\end{array}$ \\
\hline 4 & $\begin{array}{c}0.09 \\
4\end{array}$ & $\begin{array}{c}0.74 \\
4\end{array}$ & $\begin{array}{c}0.02 \\
9\end{array}$ & $\begin{array}{c}0.11 \\
5\end{array}$ & $\begin{array}{c}0.75 \\
4\end{array}$ & $\begin{array}{c}0.03 \\
6\end{array}$ & $\begin{array}{c}0.14 \\
9\end{array}$ & $\begin{array}{c}0.76 \\
7\end{array}$ & $\begin{array}{c}0.04 \\
6\end{array}$ \\
\hline 5 & $\begin{array}{c}0.12 \\
1\end{array}$ & $\begin{array}{c}0.75 \\
6\end{array}$ & $\begin{array}{c}0.03 \\
6\end{array}$ & $\begin{array}{c}0.14 \\
9\end{array}$ & $\begin{array}{c}0.76 \\
6\end{array}$ & $\begin{array}{c}0.04 \\
4\end{array}$ & $\begin{array}{c}0.19 \\
0\end{array}$ & $\begin{array}{c}0.78 \\
0\end{array}$ & $\begin{array}{c}0.05 \\
7\end{array}$ \\
\hline 6 & $\begin{array}{c}0.14 \\
9\end{array}$ & $\begin{array}{c}0.76 \\
6\end{array}$ & $\begin{array}{c}0.04 \\
3\end{array}$ & $\begin{array}{c}0.18 \\
3\end{array}$ & $\begin{array}{c}0.77 \\
7\end{array}$ & $\begin{array}{c}0.05 \\
3\end{array}$ & $\begin{array}{c}0.23 \\
4\end{array}$ & $\begin{array}{c}0.79 \\
2\end{array}$ & $\begin{array}{c}0.06 \\
6\end{array}$ \\
\hline 7 & $\begin{array}{c}0.17 \\
8\end{array}$ & $\begin{array}{c}0.77 \\
5\end{array}$ & $\begin{array}{c}0.05 \\
1\end{array}$ & $\begin{array}{c}0.21 \\
8\end{array}$ & $\begin{array}{c}0.78 \\
6\end{array}$ & $\begin{array}{c}0.06 \\
1\end{array}$ & $\begin{array}{c}0.27 \\
9\end{array}$ & $\begin{array}{c}0.80 \\
2\end{array}$ & $\begin{array}{c}0.07 \\
6\end{array}$ \\
\hline 8 & $\begin{array}{c}0.21 \\
0\end{array}$ & $\begin{array}{c}0.78 \\
3\end{array}$ & $\begin{array}{c}0.05 \\
8\end{array}$ & $\begin{array}{c}0.25 \\
6\end{array}$ & $\begin{array}{c}0.79 \\
5\end{array}$ & $\begin{array}{c}0.06 \\
9\end{array}$ & $\begin{array}{c}0.32 \\
5\end{array}$ & $\begin{array}{c}0.81 \\
2\end{array}$ & $\begin{array}{c}0.08 \\
6\end{array}$ \\
\hline 9 & $\begin{array}{c}0.24 \\
2\end{array}$ & $\begin{array}{c}0.79 \\
2\end{array}$ & $\begin{array}{c}0.06 \\
5\end{array}$ & $\begin{array}{c}0.29 \\
5\end{array}$ & $\begin{array}{c}0.80 \\
4\end{array}$ & $\begin{array}{c}0.07 \\
7\end{array}$ & $\begin{array}{c}0.37 \\
5\end{array}$ & $\begin{array}{c}0.82 \\
2 \\
\end{array}$ & $\begin{array}{c}0.09 \\
6\end{array}$ \\
\hline 10 & $\begin{array}{c}0.28 \\
1\end{array}$ & 0.8 & $\begin{array}{c}0.07 \\
2\end{array}$ & $\begin{array}{c}0.33 \\
9\end{array}$ & $\begin{array}{c}0.81 \\
3\end{array}$ & $\begin{array}{c}0.08 \\
6\end{array}$ & $\begin{array}{c}0.43 \\
0 \\
\end{array}$ & $\begin{array}{c}0.83 \\
2\end{array}$ & $\begin{array}{c}0.10 \\
6 \\
\end{array}$ \\
\hline
\end{tabular}

\section{B. Pembahasan}

\section{Karakteristik Output}

Untuk menggambarkan grafik karakteristik output keadaan arus basis $\left(\mathrm{I}_{\mathrm{B}}\right)$ harus konstan. Sehingga arus kolektor ( $\left.\mathrm{I}_{\mathrm{C}}\right)$ dan tegangan kolektor-emiter $\left(\mathrm{V}_{\mathrm{CE}}\right)$ dapat ditentukan dengan data dalam table 1 .

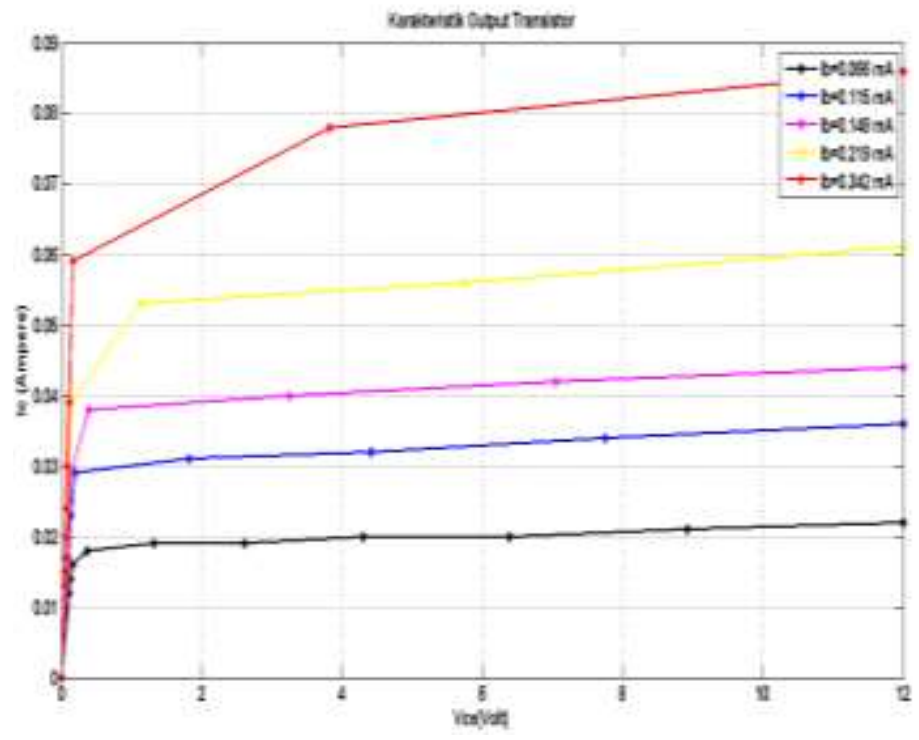

Gambar 9 Grafik hubungan antar arus kolektor $\left(\mathrm{I}_{\mathrm{C}}\right)$ dengan tegangan kolektor-emiter $\left(\mathrm{V}_{\mathrm{CE}}\right) . \mathrm{I}_{\mathrm{B}}=10 \mathrm{~mA}$

Pada grafik karakteristik output terlihat bahwa arus kolektor $\left(\mathrm{I}_{\mathrm{C}}\right)$ sebagai fungsi dari tegangan kolektor-emiter $\left(\mathrm{V}_{\mathrm{CE}}\right)$ mengalami kenaikan pada keadaan arus basis $\left(\mathrm{I}_{\mathrm{B}}\right)$ yang konstan yakni $\mathrm{I}_{\mathrm{B} 1}>\mathrm{I}_{\mathrm{B} 2}>\mathrm{I}_{\mathrm{B} 3}$. Hasil pengujian membuktikan karakteristik output yang sama dengan teori.

\section{Karakteristik Input}

Untuk menggambarkan grafik karakteristik input keadaan tegangan kolektor-emiter $\left(\mathrm{V}_{\mathrm{CE}}\right)$ harus konstan sahingga arus 
basis $\left(\mathrm{I}_{\mathrm{B}}\right)$ dan tegangan basis-emiter $\left(\mathrm{V}_{\mathrm{BE}}\right)$ dapat ditentukan dengan data dalam tabel 2 .

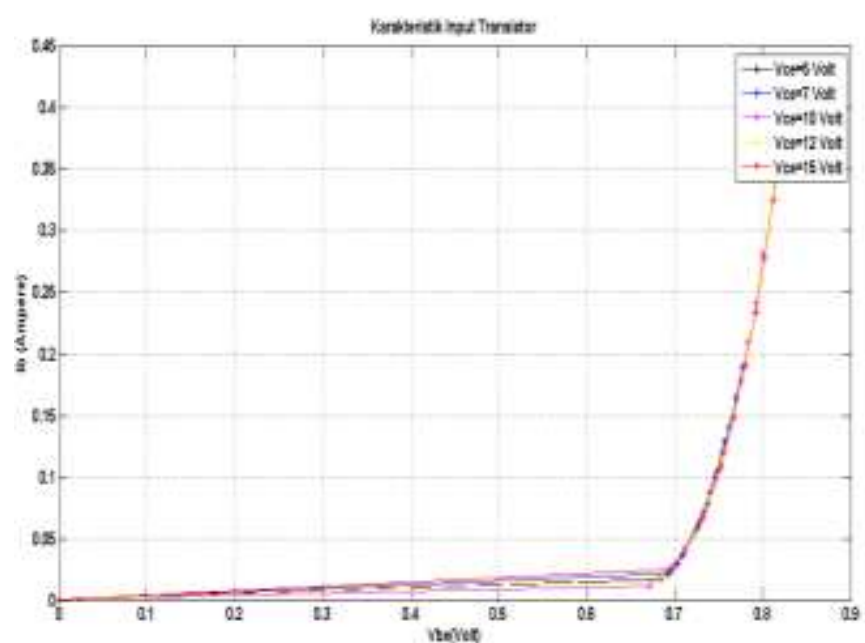

Gambar 10 karakteristik input hubungan antar arus basis-emiter (IBE) dengan tegangan basis-emiter ( $\left.\mathrm{V}_{\mathrm{BE}}\right)$.

Pada grafik karakteristik input terlihat bahwa arus basis $\left(\mathrm{I}_{\mathrm{B}}\right)$ sebagai fungsi dari tegangan basis-emiter $\left(\mathrm{V}_{\mathrm{BE}}\right)$ mengalami kenaikan pada keadaan tegangan kolektor-emiter $\left(\mathrm{V}_{\mathrm{CE}}\right)$ yang konstan yakni $\mathrm{V}_{\mathrm{CE} 1}<\mathrm{V}_{\mathrm{CE} 2}$. Hasil pengujian membuktikan karakteristik output yang sama dengan teori.

\section{KESIMPULAN}

Dari hasil percobaan didapatkan hasil yang sama dengan teori karakteristik output dan input transistor. Pada karakteristik output semakin besar arus kolektor $\left(\mathrm{I}_{\mathrm{C}}\right)$ maka semakin besar juga tegangan kolektor-emiter $\left(\mathrm{V}_{\mathrm{CE}}\right)$ pada keadaan arus basis konstan $\mathrm{I}_{\mathrm{B} 1}>\mathrm{I}_{\mathrm{B} 2}>\mathrm{I}_{\mathrm{B} 3}$. Pada karakteristik input semakin naik arus basis $\left(\mathrm{I}_{\mathrm{B}}\right)$ maka semakin besar juga tegangan basis-emiter $\left(\mathrm{V}_{\mathrm{BE}}\right)$ pada keadaan tegangan $\left(\mathrm{V}_{\mathrm{CE}}\right)$ yang konstan $\mathrm{V}_{\mathrm{CE} 1}<\mathrm{V}_{\mathrm{CE} 2}$.

\section{DAFTAR PUSTAKA}

[1] T. Widiyaman. (2017). 6 Software Simulasi Skema Rangkaian Elektronika Terbaik Versi Warriornux. Available: https://www.warriornux.com/6-softwaresimulasi-skema-rangkaian-elektronika-terbaik-versiwarriornux/

[2] Muhal. (2011). Simulasi Rangkaian Elektronika Daya dengan Multisim. Available: https://muhal.wordpress.com/2011/09/26/simulasirangkaian-elektronika-daya-dengan-multisim/

[3] R. Tandioga, Marhatang, Bahan Ajar Praktikum Elektronika Daya Program Studi Teknik Konversi Energi Makassar: Politeknik Negeri Ujung Pandang, 2008.

[4] Wikipedia. (2019). NI Multisim. Available: https://en.m.wikipedia.org/wiki/NI_Multisim
[5] R. UNIKOM. (2016). Multisim Tutorial. Available: https://repository.unikom.ac.id/49045/1/Pengantar\%20 NI\%20Circuit\%20Design_29\%20feb\%202016.docx

[6] Yang, L. H., Yang, Q., \& Sun, W. L. (2014). Statics analysis of single transistor common emitter amplifier based on Multisim 10 [J]. Modern Electronics Technique, 37(5), 127-130.

[7] Mahata, S., Maiti, A., \& Maiti, C. K. (2010, July). Costeffectiveweb-based electronics laboratory using NI MultiSim, LabVIEW and ELVIS II. In 2010 International Conference on Technology for Education (pp. 242-243). IEEE. 